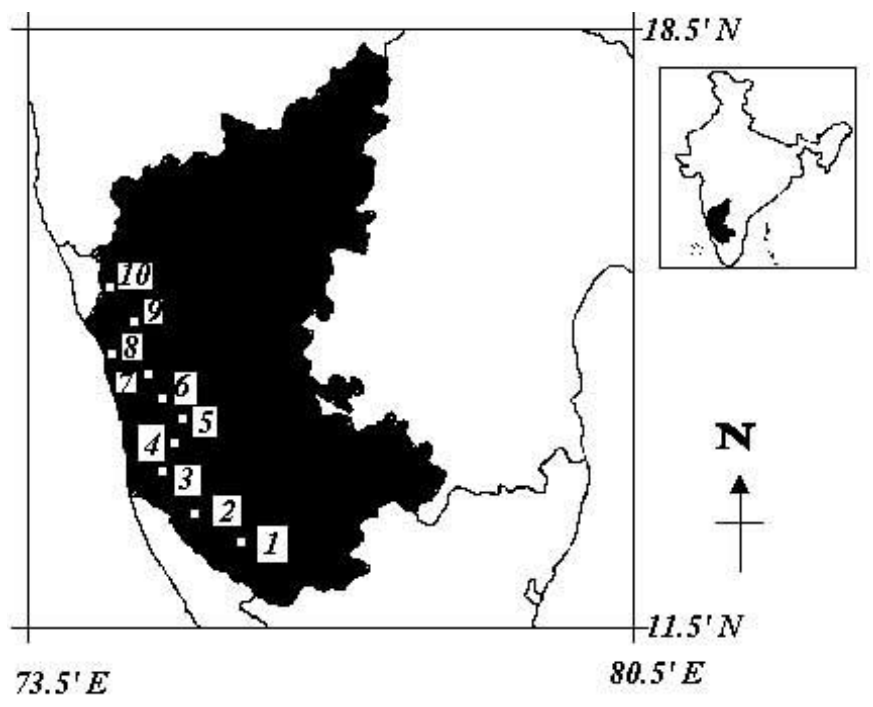

Figure 1. Map of Karnataka with the study areas. 1. Madikeri; 2. Belthangdi; 3. Bisle Ghat; 4. Kudremukh; 5. Agumbe; 6. Sagar; 7. Gersoppa; 8. Karwar; 9. Dandeli; 10. Castle Rock

Tonapi, G.T. and L. Mulherkar (1963). Studies on freshwater and amphibious Molluscs of Poona with notes on their distribution - Part II. Journal of the Bombay Natural History Society 60: 103-120.

Vaught, K.C. (1989). In: Abbott, R.T. and K.J. Boss (Eds.). A Classification of the living Mollusca. American Malacologists, Florida 32902, USA.

\section{ACKNOWLEDGEMENTS}

The authors are grateful to MoEF for the Grants to study Molluscs Of Western Ghats under the AICOPTAX scheme and to the Principal, Poornaprajna College, Udupi for extending institutional facilities.

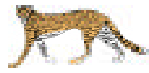

\title{
SCELIONID FAUNA OF ANNAMALAI UNIVERSITY, ANNAMALAINAGAR, TAMIL NADU
}

\section{S. Jasmin Prabu and S. Manickavasagam ${ }^{1}$}

Department of Entomology, Faculty of Agriculture, Annamalai University, Annamalainagar, Tamil Nadu 608002, India Email: ${ }^{1}$ manikavasagam_gc@sancharnet.in (corresponding author)

\begin{abstract}
Scelionid diversity of Annamalainagar, Tamil Nadu was surveyed and 23 genera under 13 tribes and three subfamilies were collected and identified. Subfamily Scelioninae is represented by 10 tribes and 17 genera, subfamily Teleasinae by two tribes and two genera and subfamily Telenominae by one tribe and four genera.
\end{abstract}

\section{KEYWORDS}

Annamalai University, Scelionidae, Scelioninae, Tamil Nadu, Teleasinae, Telenominae

Scelionidae (Platygastroidea: Hymenoptera) is a very important family of parasitoids from economic point of view. Many species play significant role in the control of excessive increase in population of several insect pests. They are widely distributed all over the world (Narendran, 2001).

This family is divided into three subfamilies viz., Scelioninae, Telenominae and Teleasinae. It contains about 150 known genera and about 3,000 known species in the world (Masner, 1993). Totally 54 genera are known from Oriental Region and 29 genera from India (Masner, 1976). Mani and Mukerjee (1976) described 13 species of different genera of scelionids from India. Gordh and Coker (1973), and, Cave and Gayler (1988) reported the attack of Geocoris (Heteroptera: Lygaeidae) eggs by many species of Telenomus (Scelionidae: Platygastroidea). Narendran and Ramesh Babu (1996-1997) have provided a key to Indian species of Calliscelio Ashmead (Hymenoptera: Scelionidae) and described six new species. Narendran (1998) described a new species of Calotelia (Hymenoptera: Scelionidae) and gave a key to five species from India. Narendran and Ramesh Babu (1996) have studied the systematics of Heptascelio Kieffer (Hymenoptera: Scelionidae). Rajmohana and Narendran (1997) erected a new subgenus Neotrimorus of genus Trimorus and also provided a modified key to the genera of Teleasinae.

Scelionids are solitary endoparasitoids of eggs of Lepidoptera, Orthoptera, Diptera, Hemiptera and Arachnida. Occasionally some species are found parasitising eggs of Coleoptera and Neuroptera also (Masner, 1976). Earlier surveys showed that no study has been carried out so far from this region of Tamil Nadu, hence an attempt was made to study the Scelionid fauna of Annamalai University Farm Premises.

\section{Study Area}

Annamalai University is located in Chidambaram, Cuddalore district $\left(11^{0} 24^{\prime} \mathrm{N} \& 79^{\circ} 44^{\prime} \mathrm{E}\right)$. It lies at an altitude of about $5 \mathrm{~m}$. The area receives water from Kollidam river. Temperature varies from $26^{\circ} \mathrm{C}$ to $36^{\circ} \mathrm{C}$. The average annual rainfall is $1,200 \mathrm{~mm}$ mostly from the northeast monsoon (October to December).

\section{Materials ANd Methods}

The scelionids were collected from Annamalai University farm 


\section{Table 1. List of scelionid fauna found in Annamalai University}

Order: Hymenoptera

Suborder: Apocrita

Superfamily: Platygastroidea

Family: Scelionidae

Subfamily: Scelioninae

Tribe: Scelionini Foerster

Scelio Latreille

Number of specimens collected: Twenty three (6M,17F)

Distribution: A worldwide genus, speciating vigorously in tropics (Masner, 1976) but represented also in much cooler parts of temperate zones. Genus already reported from India.

Remarks: Very common in the grassy lands and paddy fields. The short horned grasshoppers of the family Acrididae are the hosts of this genus.

Tribe: Calliscelionini Masner

Macroteleia Westwood

Number of specimens collected: Eighty one (76M,5F)

Distribution: A worldwide genus but centred in the tropics and subtropics. Genus already recorded in India.

Remarks: Common in paddy fields. This genus parasitizes eggs of Tettigoniidae.

\section{Anteromorpha Dodd}

Number of specimens collected: Three (3M)

Distribution: Cosmopolitan and already known from India.

Remarks: Collected from grassy lands and paddy fields.

\section{Tribe: Baryconini Kozlov}

Baryconus Foerster

Number of specimens collected: Six $(6 \mathrm{M})$

Distribution: A cosmopolitan genus, but centred in the tropics and already known from India.

Remarks: This genus parasitizes eggs of Tettigoniidae, Subfamily Phaneropterinae, laid on or inside leaves.

\section{Tribe: Psilanteridini Kozlov}

Caloteleia Westwood

Number of specimens collected: One (1M)

Distribution: Cosmopoliton and already recorded in

India. So far five species of this genus are known

from India.

Remarks: Collected from paddy nursery.

Fusicornia Risbec

Number of specimens collected: Three(2M,1F)

Distribution: Afrotropical, Oriental and Australian

Regions. Already recorded in India.

Remarks: Collected from grassy lands.

\section{Leptoteleia Kieffer}

Number of specimens collected: One (1M)

Distribution: Nearctic, Neotropical and Oriental

Regions. Already known from India.

Remarks: Collected from paddy nursery.

\section{Opisthacantha Ashmead}

Number of specimens collected: Two $(1 \mathrm{M}, 1 \mathrm{~F})$

Distribution: Neotropical, Afrotropical, Oriental and

Australian Regions. Already recorded in India.

Remarks: Collected from paddy fields.

Merriwa Dodd

Number of specimens collected: Three (3F)

Distribution: This genus already known from Oriental

Region but not from India.

Remarks: Collected from grassy lands and paddy

fields.

\section{Nyleta Dodd}

Number of specimens collected: Four $(2 \mathrm{M}, 2 \mathrm{~F})$

Distribution: Afrotropical, Oriental (but not from India) and Australian Regions.

Remarks: Collected from grassy lands.

Psilanderis Kieffer

Number of specimens collected: Two $(1 \mathrm{M}, 1 \mathrm{~F})$

Distribution: World-wide but speciating mainly in

tropics. This genus already recorded from India.

Remarks: Collected from grassy lands.

Tribe: Mantibariini Kozlov

Mantibaria Kirby

Number of specimens collected: Two (2M,1F)

Distribution: Palearctic, Afrotropical, Oriental and

Australian Regions. This genus already known from India.

Remarks: These parasitoids are associated with Mantidae.

Tribe: Platyscelionini Kozlov

Platyscelio Kieffer

Number of specimens Collected: Four (4M)

Distribution: Afrotropical, Oriental and Australian

Regions. This genus already recorded from India.

Remarks: Collected from paddy nursery. Hosts are probably the Pheneropterinae (Tettigoniidae)

Tribe: Gryonini Szabo

Gryon Haliday

Number of specimens Collected: Thirty seven (33M,4F)

Distribution: It is cosmopolitan in distribution with a great number of species in each of the main biogeographic regions. Already recorded in India.

Remarks: Collected from grassy lands and paddy

fields. This genus parasitizes eggs of Heteroptera.

Tribe: Thoronini Kozlov

Tiphodytes Bradley

Number of specimens collected: Eight (5M,3F)

Distribution: Palearctic, Nearctic, Neotropical,

Oriental and Australian Regions. Already recorded in India.

Remarks: Common near water sources. This genus parasitizes eggs of semi aquatic Heteroptera.

Tribe: Idrini Kozlov

Ceratobaeus Ashmead

Number of specimens collected: Three (3M)

Distribution: Nearctic, Neotropical, Afrotropical,

Oriental and Australian Regions. Already recorded

in India.

Remarks: Recovered from eggs of Spiders.

Tribe: Baeini Ashmead

Baeus Haliday

Number of specimens collected: Two (2M)

Distribution: Afrotropical and Oriental Regions.

Already recorded in India.

Remarks: Recovered from eggs of spiders.

Subfamily: Teleasinae

Tribe: Teleasini Ashmead

Trimorus Foerster

Number of specimens collected: Three (3M)

Distribution: Nearly world-wide in distribution. There are 27 species known from Oriental Region, out of which 20 are so far reported from India.

Remarks: This genus parasitizes eggs of Carabidae (Coleoptera).

Tribe: Xenomerini Kozlov

Xenomerus Walker

Number of specimens collected: Ten (7M,3F)
Distribution: Palearctic, Neotropical, Afrotropical, Oriental (but not from India) and Australian Regions. Remarks: Collected from grassy lands.

Subfamily: Telenominae

Tribe: Telenomini Thomson

Trissolcus Ashmead

Number of specimens collected: Seven $(6 \mathrm{M}, 1 \mathrm{~F})$

Distribution: Virtually world-wide, speciating in both temperate and tropical zones. Already recorded in India.

Remarks: Collected from paddy fields, egg parasitoids of Heteroptera.

\section{Aporophlebus Kozlov}

Number of specimens collected: Three (3M)

Distribution: Palearctic, Afrotropical, Oriental and

Australian Regions. Already recorded in India.

Remarks: Collected from paddy fields.

Psix Kozlov

Number of specimens collected: Fifty $(39 \mathrm{M}, 11 \mathrm{~F})$

Distribution: World-wide in distribution. Already recorded in India.

Remarks: Collected from paddy fields, egg parasitoids of Pentatomidae.

\section{Telenomus Haliday}

Number of specimens Collected: Three thousand two hundred and seventy (@\&:B\& ratio is 3:1).

Distribution: World-wide in distribution and already known from India.

Remarks: These parasitoids were collected from paddy fields. Out of 3,270 parasitoids 3,169 were collected through rearing of rice stem borer egg masses. 220 Stem borer egg masses from paddy field were collected and observed for emergence of parasitoids. Surprisingly more than $80 \%$ of the egg masses were parasitized. Totally 3,528 parasitoids were recovered. Out of this 3,270 were Scelionids and the remaining were Eulophids and Trichogrammatids (Prabu \& Manickavasagam, 2003) 
Table 2. Details of Scelionid parasitoids collected during 2001-2003

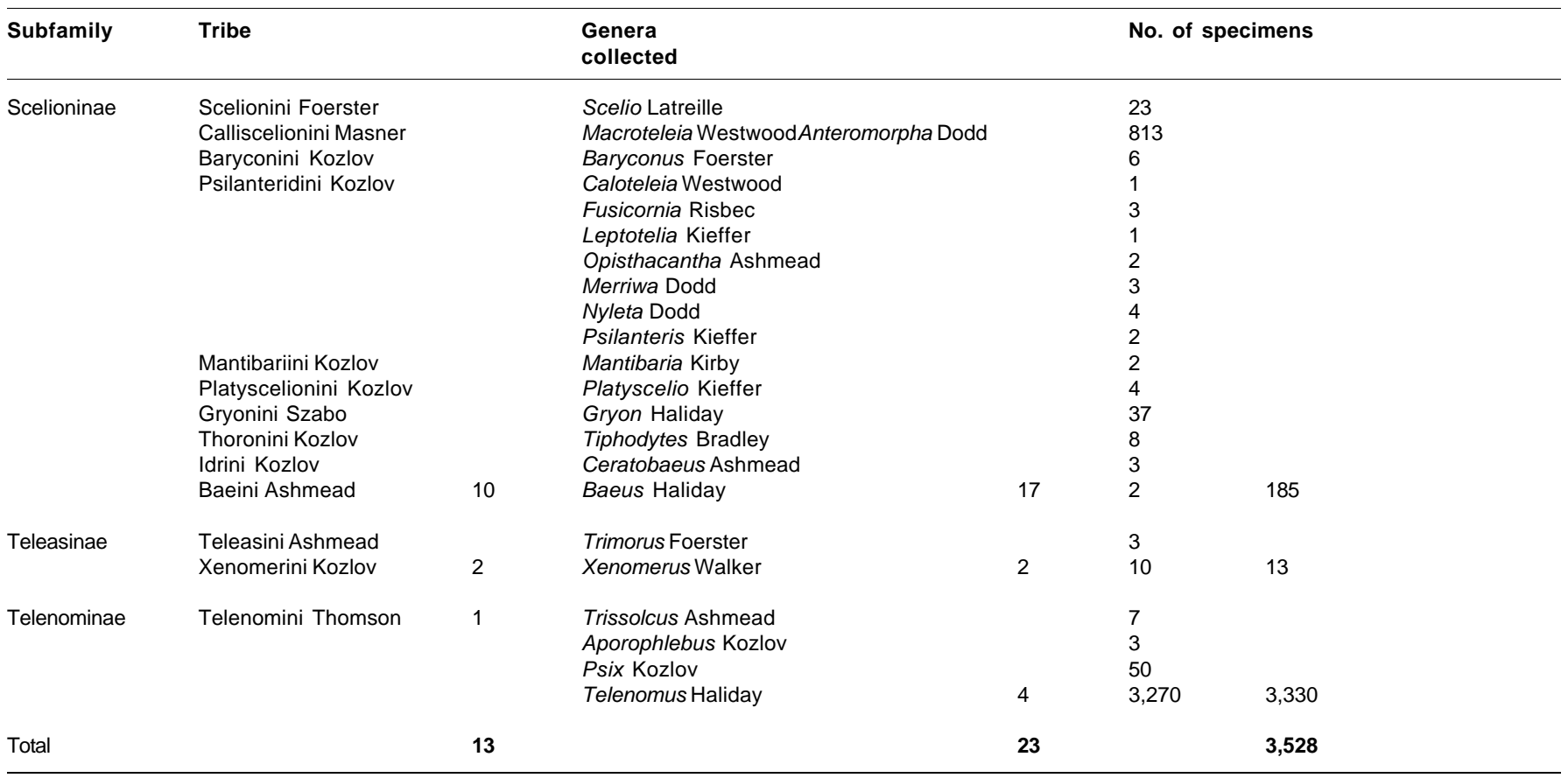

premises, Chidambaram in Tamil Nadu using triangular nets specially made for the purpose as described by Noyes (1982). The specimens were mounted on cards made by point punch (BioQuip $^{\mathrm{TM}}$, USA, Catalogue No: 1150A) and pinned using Newey Patent Entomological pins No.12 (Made in UK). The observations were made using stereozoom (model STZ.B) microscope.

\section{Discussion}

The number of parasitoids collected and identified as scelionids was 3,528. All the three subfamilies which are already reported viz., Scelioninae, Teleasinae and Telenominae are represented in the present study also. The number of parasitoids collected under the subfamily Scelioninae was 185 . Though the number of parasitoids collected was less under this subfamily, the number of tribes (10) and genera (17) identified were more than the other two subfamilies. The parasitoids collected under the subfamily Teleasinae were 13 . Though the number of parasitoids collected under this subfamily was less, this represents all the two recorded tribes viz., Teleasini and Xenomerini. Although the subfamily, Telenominae constitutes the maximum number of collected parasitoids $(3,330)$, Telenomini is the only tribe recorded so far globally and here too it is represented by four genera (Table 1).

\section{REFERENCES}

Cave, R.D. and M.J. Gaylor (1988). Parasitism of Geocoris (Heteroptera: Lygaeidae) eggs by Telenomus (Hymenoptera: Scelionidae) in Alabama. Environmental Entomology 17(6): 945-951.

Gordh, G. and R.A. Coker (1973). A new species of Telenomus (Hymenoptera: Proctotrupoidea) parasitic on Geocoris (Hemiptera: Lygaeidae) in California. Canadian Entomologist 105: 1407-1411.

Prabu, S.J. and S. Manickavasagam (2003). Parasitoids of rice stem borer eggmass, p.39. Paper Presented in National Symposium on Bio-
Management of Insect Pests held at Annamalai University, Tamil Nadu, India, March 29-31, 2003.

Mani, M.S. and M.K. Mukerjee (1976). On some Baeinae (Proctotrupoidea: Scelionidae) from India. Oriental Insects 10(4): 497526.

Masner, L. (1976). Revisionary notes and keys to world genera of Scelionidae (Hymenoptera: Proctotrupoidea). Memoirs of Entomological Society of Canada 97: 1-87.

Masner, L. (1993). Superfamilies Proctotrupoidea, Platygastroidea and Ceraphronoidea, pp. 558-565. In: Goulet, H. and J.T. Huber (eds.) Hymenoptera of the World: An Identification Guide to Families. Agriculture Canada Publication, Canada.

Narendran, T.C. (1998). A new species and a key to species of Calotelea Westwood (Hymenoptera: Scelionidae) from India. Proceedings of the Zoological Society of Calcutta 51(1): 70-74.

Narendran, T.C. (2001). Parastitic Hymenoptera and Biological Control. Palani Paramount Publications, Palani, 190pp.

Narendran, T.C. and M.G. Ramesh Babu (1996). On the systematics of Heptascelio Kieffer (Hymenoptera: Scelionidae). Uttar Pradesh Journal of Zoology 16(2): 89-93.

Narendran, T.C. and M.G. Ramesh Babu (1996-1997). A systematic study of six new species of Calliscelio Ashmead (Hymenoptera: Scelionidae) of India with a key to Indian species. Journal of the Zoological Society of Kerala 687: 1-10.

Noyes, J.S. (1982). Collecting and preserving chalcid wasps. Journal of Natural History 16: 315-334.

Rajmohana, K. and T.C. Narendran (1997). A remarkable new subgenus Neotrimorus of Trimorus Foerster (Hymenoptera: Scelionidae) from India. Journal of Advanced Zoology 18(1): 33-37.

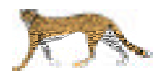

